\title{
Evaluation and Analysis of Student Academic Burden: A Global Perspective
}

\author{
Jinming Liu, Ping Huang \\ Fort Erie International Academy of Canada, ON L2A 3T7, Canada
}

\begin{abstract}
Student academic burden exists to varying degrees throughout the world. To reach a comprehensive and unbiased understanding of the roles of academic burden, this paper explores academic burden from different viewpoints and summarizes existing assessment indexes for it. Factors correlated with student academic burden are examined and detailed evaluations on both its advantages and disadvantages are conducted. Some suggestions are proposed to better address this issue for the benefit of student healthy growth and development.
\end{abstract}

Science Insights Education Frontiers 2021; 10(2):1423-1437.

Doi: 10.15354/sief.21.or062

How to Cite: Liu, J., \& Huang, P. (2021). Evaluation and analysis of student academic burden: A global perspective. Science Insights Education Frontiers, 10(2):1423-1437.

Keywords: Student Learning, Student Academic Burden, Teaching Efficacy, Learning Efficacy, Factors Correlated with Academic Burden

About the Author: Jinming Liu, Fort Erie International Academy of Canada, 474 Central Ave, Fort Erie, ON L2A 3T7, Canada.E-mail: info@feia.ca

Correspondence to: Ping Huang, Fort Erie International Academy of Canada, 474 Central Ave, Fort Erie, ON L2A 3T7, Canada.E-mail: hp20210101@163.com

Conflict of Interests: None.

(c) 2021 Insights Publisher. All rights reserved.

cc) (i) (-) Creative Commons NonCommercial CC BY-NC: This article is distributed under the terms of the Creative Commons Attribution-NonCommercial 4.0 License (http://www.creativecommons.org/licenses/by$\mathrm{nc} / 4.0 /$ ) which permits non-commercial use, reproduction and distribution of the work without further permission provided the original work is attributed by the Insights Publisher. 


\section{Introduction}

A CADEMIC burden refers to the effect of schoolwork loads on students' physical and mental condition. International studies rarely mention the concept of 1 academic burden. Instead, they examine the effects of weekly learning hours and homework loads from different angles, generating expressions similar to academic burden, such as academic burnout, academic pressure, academic anxiety and academic depression. In fact, academic burden exists worldwide and especially in Southeast Asian countries where, even at basic education levels, excessive academic burden created by entrance examinations for schools poses a serious problem. Existing research indicates that appropriate levels of academic burden can promote learning outcomes, while levels that are too high will lead to psychological and behavioral problems in students. Thus, scientific evaluation and analysis rather than biased comments are needed for a rational assessment of student workload. This paper uses a global perspective to examine different explanations of academic burden and summarize suggested assessment indexes. Variables at the level of students, families, teachers, and society that correlate with student academic burden are discussed and the benefits of appropriate academic burden and risks of excessive academic burden are fully analyzed. With a humanistic stance, we also put forward suggestions to rationalize student academic burden by focusing on the comprehensive development of individuals and optimizing teaching and learning methods.

\section{Conceptual Analysis of Academic Burden}

The concept of 'academic burden' varies among different national education environments and systems. Research perspectives and materials of scholars similarly vary. In Southeast Asian countries such as China, Singapore, Japan and South Korea, where student learning pressure is typically intense, scholars mainly interpret academic burden as the stressful experience of students as they attempt to adapt to the current learning environment and the time and energy required by students for examinations and homework (Song \& Yang, 2014). Similar expressions such as schoolwork burden, learning burden and student burden are also used.

In contrast, for Western countries, e.g., the United States, Britain, and Finland, in which 'happy learning' is advocated, scholars less commonly mention academic burden. Instead, scholars pay attention to the negative effects caused by homework and study, such as physical dysfunction, emotional fluctuation, anxiety, depression, negative and passive attitudes, personality disorders, confusion and declines in efficiencies. Thus, in the 1980s, researchers from Western countries, borrowing from the working world phrase 'job burnout', created expressions such as learning burnout, academic burnout, academic pressure and academic anxiety to describe the physical and mental damage to students caused by long-term and highly demanding schoolwork (Pines \& Kafry, 1980; Meier \& Schmeck, 1985). 
In Western countries, therefore, scholars focus on the sequential influence of academic burden rather than the burden itself. In this paper, we consider both academic burden and its effects combined, in an attempt to present a comprehensive view of academic burden. The connotations of academic burden are examined from various angles, as described in the rest of this section, below.

\section{Physical and Mental Burden}

Academic burden can be divided into physical burden and mental burden. Physical burden refers to the consumption of physical energy; this is proportional to learning time and learning intensity and has cumulative effects. Mental burden refers to the consumption of mental energy. It is closely related to students' psychological burden of learning, their status and role among peers, and evaluation from others, especially educators (including the psychological burden caused by the expectations and requirements of parents and teachers). Physical and mental burden are positively correlated.

\section{Subject Curriculum and Activity Curriculum Burden}

In terms of content, academic burden encompasses a subject curriculum and an activity curriculum burden. The subject curriculum burden is the physical and mental effort made by learners to fulfil subject requirements, including requirements for schoolwork and extra-curriculum learning. The activity curriculum burden comes from the time and energy investment required to develop social skills and practical abilities through social practice, team activities and social activities.

\section{On-campus and Off-campus Academic Burden}

In terms of location, academic burden includes both on-campus and off-campus burdens. On-campus burden is directly related to school learning and is characterized by strong planning, low independence, and high intensity. Learning efficacy and intensity both effect on-campus burden. Off-campus burden comes from home learning and community learning; extra-curriculum tutoring, and training are its major sources.

\section{Assessment Indexes of Student Academic Burden}

Scholars have not reached a consensus about survey and assessment indexes of academic burden. In Western countries, most studies are conducted using the 'education index system.' In Southeast Asian countries such as China, Singapore, Japan and Korea, scholars pay more attention to academic burden assessment indexes than their Western counterparts. Taking foreign national education index systems as references, this paper puts forward an academic burden assessment index framework that incorporates schoolwork, physiological and psychological burdens.

\section{Schoolwork Burden}




\section{Time Investment in Learning}

Time investment in learning includes class time, homework time and extra tutoring time. Class time refers to the time that students spend on learning activities in the classroom every day (excluding self-study, after class activities and physical exercises). There are two kinds of homework time: time for homework assigned by schoolteachers and time for homework from outside the school, which might be homework assigned by parents or by tutorial agencies. Similarly, there are also two kinds of tutorial time: time for oncampus tutoring required by schools and time for home tutoring or tutoring provided by tutorial agencies.

\section{Difficulty of Learning Tasks}

The key factor affecting the time investment required for learning is the difficulty of learning tasks, including the difficulty of subjects, homework and exams. Difficulty is determined by the specific requirements for each subject as determined by the quality standards formulated by each country, such as the education supervision and assessment index system in the UK (Abdgula, 2008), the guidelines for the assessment of compulsory education schools in Japan (Nakayasu, 2016) and the comprehensive assessment index framework for the quality of primary and secondary education issued by the Ministry of Education of China in 2013 (Wang, 2014). All put forward certain requirements that students must meet in learning tasks, such as subjects and homework.

\section{Schoolwork Quality}

Schoolwork quality influences student learning efficacy, which further affects academic burden. Schoolwork quality includes the effectiveness of teaching, homework and examinations (tests). However, requirements for teaching effectiveness differ among different schools of education and standards for the effectiveness of teaching, homework and examinations vary. Therefore, evaluation on the effectiveness of teaching, homework and examinations are somewhat subjective.

\section{Physiological Burden}

In index frameworks of academic quality surveys in various countries, physical health is considered an important index of sustainable study. Body mass index (BMI) and uncorrected visual acuity (UCVA) are regarded as comparatively objective metrics that can be applied to academic burden assessment. In addition, students' sleep time is affected by academic burden level. Thus, sleep time, BMI and UCVA are included in the survey index framework.

\section{Sleep Time}


Student sleep time refers to the average total sleep time (including naps) of students every day during school sessions. An increase in student learning load leads to a reduction in student sleep time. It is one of the core indexes for students' physical burden assessment.

\section{Degree of Myopia}

In the "International Myopia Institute (IMI) White Papers" published by the International Myopia Institute, myopia is a kind of ametropia, in which the light entering the eye parallel to the optical axis is focused in front of the retinal membrane when the eye adjustment is relaxed. This is typically due to the long anterior-posterior diameter of the eyeball or excessive corneal bending and/or increased lens power (Wolffsohn et al., 2019). Although student academic burden is not the only cause of myopia and other individual physiological causes exist, overall myopia rate of students and its change in a school can reflect academic burden to a certain extent, as students' main activity is learning.

\section{BMI}

Body Mass Index, an indicator of total body fat, measures the degree to which an individual is overweight or obese and is commonly used as a standard for the level of healthiness throughout the world. In addition, the score calculated by BMI can provide information on the status of nutrition. Thus, BMI is adopted instead of the obesity index for assessments of academic burden because health level is not only negatively correlated with obesity but also with other factors such as malnutrition.

\section{Psychological Burden}

Students' psychological burden comes mainly from a conflict between the requirements and expectations of families, schools and society of students' various roles, and the students' interest and ability in playing these roles. In Rong's (2017) study, learning pressure is measured as a spectrum from learning happiness to learning fatigue to learning anxiety to learning weariness. These four measures reflect changes in students' psychological pressure arising from academic burden. Among them, learning happiness refers to students that have a high satisfaction with their learning environment and academic performance. The transformation from learning fatigue to learning weariness reflects possible changes in a students' mood from depression to fear, then to boredom and indifference as learning pressure increases.

\section{Factors Correlated with Students' Perception of Aca- demic Burden}

\section{Student Learning Efficacy}


Many researchers have proposed that academic burden is subjective to some extent and that it differs in its effect for different individuals. Ai (2015) suggested that, to achieve learning goals, learners will proactively make time and energy investment in study. The amount of investment is related not only to difficulty of the learning tasks but also to the students' learning willingness, learning ability and, especially, their learning methods. Likewise, Jin and Gao (2016) noted that learning efficacy, including students' selfefficacy and actual ability of learning, is a key factor affecting student academic burden. Individual differences in learning efficacy significantly affect the results of homework. Trautwein et al. (2006) found that the assumption that 'students assigned with heavy loads of high-quality homework will get better grades' is tenable only when emotional variables are incorporated into the analysis; it is true only for students that have few negative emotions when doing homework. This indicates that students' subjective feelings are also closely related to the acceptability of burden. Students with good learning methods and strong learning ability will complete learning tasks effectively and have a good emotional experience, which in turn motivates them to make further efforts.

\section{Teaching Efficacy}

There is a consensus in academia that improvement in teaching efficacy helps reduce student academic burden. Liu and Zhu's (2018) meta-analysis on the effect of teaching efficacy on academic burden indicates that teaching efficacy moderately reduces students' academic burden and that among all the elements of teaching efficacy, teaching environment (here mainly referring to interpersonal relationships at school) reduces students' learning pressure and homework time most significantly. Good teacherstudent relationships and teachers' identity with the school are remarkable in their ability to alleviate student academic burden. Teachers' fair treatment of students, open attitudes towards students' opinions, encouragement of, and trust in, students and their belief that students' schooling is part of their overall development make students feel that learning is a happy and meaningful journey. Building a good teaching environment should thus be the top priority in enhancing teaching efficacy. Teaching efficacy primarily works on students' perception of academic burden and high teaching efficacy can reduce students' academic burden by alleviating learning stress and increasing learning interest.

\section{Parental Expectations}

Some scholars have suggested that the mechanism of parental expectations is similar to the Rosenthal effect, with parental expectation engendered according to the mechanism of "vision - expectation - action - reaction - acceptance - externalization" (Ren, 2004). Following this mechanism, parents generate expectations of their children's achievements (academic achievement, highest education, social achievement), moral character and interpersonal relationships. 
Proper parental expectations can meet children's psychological needs for dependence, enable good psychological experiences, stimulate learning activities, and increase intellectual potential in their children. Parental expectations also contribute to a child's formation of self-expectation. However, excessive parental expectations tend to induce rebelliousness in children and thus affect their school behavior negatively.

According to sociology, parents tend to transfer the pressure and anxiety they feel in social comparisons of their children to other students, feeling obligated to discipline their children and urge their development (Garcia, Tor, \& Schiff, 2013). When this comparative pressure exceeds the students' mental endurance, it leads to a psychological burden on the student.

\section{Social Demands for Educational Value}

Social expectations of education are that it meets the needs of social development, and that individual development is consistent with social development. From the perspective of economics, scholars such as Schultz (1961), Becker (1962) and Mincer (1958) argued that human capital, critical to economic development, could generally be obtained through education. The increase in a well-educated population implies a higher level of labor productivity and a greater ability to introduce advanced technology. As a result, students are not only affected by academic burden itself, but they also experience stress from social expectations of education. In the context of fierce competition for school progression and potential challenges to employment in future, students become the bearers of multiple burdens.

\section{Rational Evaluation and Analysis on the Effects of Student Academic Burden}

\section{Reasonable Academic Burden}

For students, there are two categories of academic burden: reasonable burden and excessive burden. Reasonable academic burden is the necessary pressure associated with learning activities, the pressure that students must experience to forge their individuality and personality and learn the basic knowledge and skills necessary to meet the requirements of present-day society. Reasonable academic burden will stimulate a student's progress and promote a student's development.

\section{Improving Student Character}

Reasonable burden and responsibility are not only necessary for student growth, but also an indispensable part of a student's social adaptation. Societal development requires that every generation must bear some pressure, suffering and burden during childhood. The complexity of modern society challenges people's stress tolerance. If students want to win in future competitions or cooperate successfully with others, they 
must have a strong resistance to frustration as well as a strong personality and adaptability. Students' willingness to take on academic responsibilities and challenges undoubtedly plays a critical role in cultivating a student's resilient personality.

\section{Beneficial to Student Mastery of Basic Learning Skills}

Learning is typically a tense and monotonous activity, demanding strong willpower, positive emotional elements, and cognitive abilities. At the stage of studying basic knowledge, when students are not ready to understand the significance and value of study, too much emphasis on learning interest and freedom is not conducive to students' mastery of basic knowledge and basic learning skills.

To lay a solid foundation for lifetime study, students must undergo certain basic knowledge collection and method training. A reasonable level of compulsory academic burden resulting from this process is not harmful to students' physical and mental health. Rather, it promotes students' comprehensive development (Qi \& Sun, 2016).

\section{Ameliorating Overall National Quality}

A history of world educational development indicates that academic burden affects improvement of the national basic education quality. The contemporary era has witnessed radical reforms in education. In drafting educational reform policies, whether to increase or reduce student academic burden is often a hotly debated topic in discussion.

Arguments on this topic originated in the USA. Under the influence of progressivism in education, the United States advocated "child centrism" in the early 20th century, emphasizing children's freedom, interests, and outdoor activities, and giving up training, burdensome studies and strict academic standards. In reducing student academic burden, the country experienced a decline in student academic and moral levels, and a rise in crime rate (Beck, 1942). The successful launch of the Soviet Union's first man-made satellite in 1957 awakened American society to the importance of basic education. As essentialism began to prevail, importance was again attached to the idea of strengthening basic education and cognitive training. In 1983, under the policy of "providing leadership, constructive criticism and effective help to primary and secondary schools," the National Education Commission led by Bell submitted to the U.S. Secretary of Education at the time the report, "A Nation at Risk: The Imperative for Educational Reform," which exposed various flaws in American education, the sequential crises faced by the system and then put forward suggestions on teaching content, standards, leadership and funding (Gardner, 1983).

The former Soviet Union and Japan underwent similar educational reforms. To improve student mastery of knowledge in compulsory subjects, the former Soviet Union has implemented a series of educational reforms since the 1930s, such as reinstating traditional subject-based teaching, conducting class teaching, adopting uniform textbooks for long-term use, and reducing teaching time in non-compulsory subjects. This reform resulted not only in increases in student academic burden, but also in advances 
in educational quality, laying a solid foundation for the Soviet Union's rapid growth in science and technology. Subsequently, numerous reform policies have been issued for the purpose of producing higher-quality labor. In the 1980s, after entering a new phase of educational reform, the former Soviet Union started discussions on academic burden from the perspective of student comprehensive development and improvement in psychological health. In view of the new requirements for talent in modern society, students' sense of responsibility and obligation in learning was emphasized and the importance of academic burden highlighted.

Corresponding to Japan's “Third Voyage" plan in the early 1980s (an attempt to transform Japan from an economic power to a political power), the country began its third educational reform. Although changes have been made to the so-called "hell-like" and "highly uniform" education system, with efforts made to incorporate "relaxation," "happiness" and "personality development," student academic burden has not lightened significantly. In Japan, academic pressure has become essential to cultivating students' sense of responsibility and setback-resistance. In addition, adequate basic knowledge collection and relevant learning skills training are emphasized as fundamental for obtaining higher levels of knowledge and skills.

The evolution of educational policies in the United States, the Soviet Union and Japan indicates that an appropriate student academic burden plays an important role in the development of a country and its education. The improvement of a nation's basic quality of education is often based on maintaining appropriate levels of academic burden.

\section{Excessive Academic Burden}

Excessive academic burden, in contrast, can lead to negative feelings such as tension, anxiety, aversion, fear, etc. The consequences of these feelings are counter to students' healthy growth, as expounded on below.

\section{Inducing Physical Unfitness and Illnesses}

Inappropriate levels of academic burden can cause a variety of illnesses. Honkonen et al. (2006) in their study of job burnout, noted that job stress erodes human health over time, leading to skeletal muscle diseases, cardiovascular diseases, and some allergic reactions. Many scholars refer to this conclusion in their study of academic burden. Nevertheless, Kahill (1988) asserts that there is insufficient evidence to attribute systemic diseases to academic burden and that only physical conditions such as insomnia, nightmares, headache, stomach pain, intestinal flora imbalance and fatigue are likely to be significantly and positively correlated with academic burden.

In addition, an unduly heavy academic burden deprives students of sufficient time for rest and physical exercise. The "2020 Blue Paper: Report on China National Mental Health Development (2019-2020)" released by the Institute of Psychology of the China Academy of Sciences in 2021 shows that standards for sleep time are not met 
by $95.5 \%$ of primary school students, $90.8 \%$ of junior middle school students and $84.1 \%$ of senior middle school students in China (Fu, Zhang, \& Chen, 2021).

Insufficient rest and exercise time can lead to poor physical function, rapid decline in visual acuity and rapid changes in body mass. Zhu et al. (2017, December 24) associated academic burden with grade level prevalence of students' physical activity and sedentary behaviors, analyzing the data of 48118 children in Shanghai in the 2014 survey of Physical Fitness and Health Index of Children and Adolescents (PFHICA). Children in transition grades 6 and 9 (when they face entrance exams) and throughout all high school years were less physically active than other grades. This occurs despite these children giving up most of their screen viewing time (on mobile phones, for example). Therefore, academic burden appears to be the main reason for lack of adequate physical activity. Morgan et al. (2012) emphasized in his study that myopia has become a major problem facing students in Southeast Asian countries and that the high rates of myopia are related to the increase in academic pressure and change in lifestyle, as both reduce children's time spent on outside activities.

\section{Causing Psychological Burden and Harm}

Existing research indicates that long-term excessive academic burden has a direct negative impact on student emotions and psychology, manifested as increased depression levels. Depression is a state of mind that presents as gloominess, low spirits and negative attitudes towards everything. To students, unfavorable factors such as dramatic change in the environment and increased academic burden often provoke prolonged and drastic psychological reactions that can lead to depression (Mei et al., 2021).

Bossy (2000) investigated the stress faced by Japanese students, especially high school students and found that the stress experienced by Japanese students while in pursuit of academic achievements, especially when preparing for college entrance examinations, is harmful to their mental and physical health. Extreme cases like bullying and school-related suicide may occur.

A cross-sectional study conducted by Zhu et al. (2021) found similar results. In a sample of 1,533 adolescents in Eastern China that examined the effect of academic burden on physical activity and sleep time, and its correlation with anxiety and depression. The study results confirmed that academic burden is negatively correlated with physical activity and sleep time and positively correlated with levels of anxiety and depression.

\section{Lowering Student Learning Effectiveness}

Deb, Strodl, \& Sun (2015) conducted a survey by questionnaire of the correlation between academic burden and student mental health. One hundred and ninety senior middle school students in grades 11 and 12 (average age $=16.72$ years) from three government-funded schools and three private schools in Calcutta, India, participated. Nearly two-thirds $(63.5 \%)$ of students reported feeling stressed due to academic pressure. Fur- 
ther, academic burnout was positively correlated to academic pressure and a student's reaction to pressure. Prolonged academic burnout significantly compromised learning outcomes.

\section{Hindering Individual Overall Development}

An individual's comprehensive development refers to their lifelong development in physical, cognitive, social, and emotional dimensions. Some scholars define inappropriate academic burden as any that leads to students experiencing negative feelings during learning tasks and while working in the study environment. It is difficult to cultivate students' interests and self-motivation in learning when they have strong feelings of being compelled to study. Forced study damages self-reliance and self-confidence in learning and substitutes simplified training for reflection on learning methods. As a result, learning becomes a process of monotonous memorization while neglecting higher order thinking abilities such as imagination, logic, and creativity (Zhang, 2020). Moreover, the heavy schoolwork loads and long learning hours typical of excessive academic burden reduce individuals' sport and social time, leading to deficiencies in social skills. Thus, an academic burden hinders the all-round development of individuals.

\section{Suggestions Based on Humanistic Thought}

The goal of current research on academic burden is scientifically judge what levels of burden can best promote student growth, in which the value of students as human beings is emphasized. Examination on academic burden is not meant to simply reduce student learning loads, or to justify pushing students forward with heavy workload, but rather to determine what levels of burden is beneficial to their healthy growth and longterm development.

\section{A Rational Outlook on Education should be Adopted to Avoid Either Exaggerating or Ignoring the Impact of Academic Burden.}

The essential goal of education is to cultivate individuals with integrity, that is, "whole" human beings. Education is responsible not only for imparting knowledge and culture, but also for the construction of a student's spiritual world, including a reasonable outlook on life and good values. However, the prevalent concepts of "omnipotent education" and "useless education" are both biased against this educational essence. At one extreme, exaggeration of the role of learning loads can leave students overwhelmed by meaningless and repetitive exercises and training. At the other extreme, ignoring the value of a proper school workload and delivering prejudiced judgements on education to the public can also mislead students, impeding their ability to acquire initiative and a proactive approach to study and life. It is thus key to bear in mind that in education the student is an end rather than a means. To meet social requirements for education in so- 
cietal development, more emphasis should be placed on a student's all-round growth (Meng, 2017). In view of this, academic burden should be re-examined. Any discussion on appropriate levels of academic burden must be centered on the healthy development of individuals.

\section{Learning and Teaching Methods should be Improved to Enhance Study Efficiency and Effectiveness.}

Attention needs be paid to the actual status of each student's learning, including their feelings and experiences of learning, cognitive abilities, emotions regarding school, and behavioral disposition. Considerations of individual perceptions of academic burden can help improve each student's learning efficiency, raise the student's quality of life, and reduce students' physical and mental burden (Ai \& Wang, 2016). In addition, teachers should increase their awareness of the advantages and disadvantages of academic burden and be committed to improving teaching methods to better regulate students' academic burden (Li \& Luo, 2014).

\section{The Quality of Student Assignments should be Raised, and the Effect of Marginal Utility Avoided.}

In December 2012, the Organization for Economic Cooperation and Development (OECD, 2012, December 3) released the "Program for International Student Assessment (PISA) 2021 Results." Among the students participating in the survey, the average homework time of students in Shanghai, China, was 13.8 hours a week, or less than 2 hours a day, which, while hardly a heavy academic burden, was far from being efficient. In contrast, Korean students spent an average of three hours a week on homework, but their scores were only 45 points lower than those of Shanghai students. Although a large quantity of exercise is helpful to students' memorization and mastery of knowledge, the rule of diminishing marginal utility is also applicable to homogeneous exercises; that is, with an increase in the quantity of similar exercises, the benefits from increased exercises will diminish. This phenomenon frequently occurs in Southeast Asian countries, where, affected by the entrance examination systems, students tend to practice repetitive exercises to cope with the entrance examinations. A reduction in academic burden does not simply mean lessening the quantity of homework and tests. Rather, it is about optimizing assignment quality. To do so, we should try to remove the monotonous, repetitive, and imitative teaching contents and exercises, and make oncampus and off-campus assignments more effective and inspiring. Moreover, the difficulty of homework should vary among students according to their abilities. Information technology can be employed to personalize assignments to the specific academic levels of individuals and to innovate new forms and content of homework.

Education is an essential component of human socialization. While education exists, academic burden will be present. The necessity and validity of an appropriate 
academic burden have been fully discussed and factors influencing students' perceptions of it are examined in this paper. Further research should focus on methods to make academic burdens more friendly and humanistic to students and on how to optimize educational methodology. Social development and the concomitant advances in technology have dramatically changed the way people work and live. Surely, these advances will make significant differences to students' learning styles in the future.

\section{References}

Abdulla, A. (2008). Educational supervision: A new challenge. Journal of the Royal Society of Medicine, 101(1):6. DOI:

https://doi.org/10.1258/jrsm.2007.070342

Ai, X. (2015). Academic burden of primary and secondary school students: Concept, attribution and solutions in the context of current basic education curriculum reform. Journal of Southwest University (Social Science Edition), 2015(4):93-97. DOI:

https://doi.org/10.13718/j.cnki.xdsk.2015.04. $\underline{012}$

Ai, X., \& Wang, L. (2016). Academic burden of primary and secondary school students: level, characteristics, and implications. Educational Research, 2016(8):77-84.

Beck, R.H. (1942). American progressive education, 1875-1930. Yale University.

Becker, G.S. (1962). Investment in human capital: A theoretical analysis. Journal of Political Economy, 70(5, Part 2):9-49. DOI: https://doi.org/10.1086/258724

Bossy, S. (2000). Academic pressure and impact on Japanese students. McGill Journal of Education, 35(1):71-84.

Deb, S., Strodl, E., \& Sun, J.D. (2015). Academic stress, parental pressure, anxiety, and mental health among Indian high school students. International Journal of Psychology and Behavioral Science, 5(1):26-34. DOI: https://10.5923/i.ijpbs.20150501.04

Fu, X.L., Zhang, K., \& Chen, X.F. (2021). Report on China national mental health devel- opment (2019-2020). Beijing: Social Sciences Academic Press (China). ISSBN:

9787520178150

Garcia, S.M., Tor, A., \& Schiff, T.M. (2013).

The psychology of competition: A social comparison perspective. Perspectives on Psychological Science, 8(6):634-650. DOI: https://doi.org/10.1177/1745691613504114

Gardner, D.P. (1983). A Nation at Risk: The Imperative for Educational Reform. An Open Letter to the American People. A Report to the Nation and the Secretary of Education.

Honkonen, T., Ahola, K., Pertovaara, M., Isometsä, E., Kalimo, R., Nykyri, E., Aromaa, A., \& Lönnqvist, J. (2006). The association between burnout and physical illness in the general population-results from the Finnish Health 2000 Study. Journal of Psychosomatic Research, 61(1):59-66. DOI: https://doi.org/10.1016/j.jpsychores.2005.10. $\underline{002}$

Jin, Y.M., \& Gao, Y.Q. (2016). Burden reduction based on learning efficiency. Journal of Teaching and Management, 2016(30):14-17.

Kahill, S. (1988). Symptoms of professional burnout: A review of the empirical evidence. Canadian Psychology, 29(3):284. DOI: https://doi.org/10.1037/h0079772

Li, H.M. \& Luo, S.Q. (2014). Teaching efficacy and the issue of academic burden. Research on Educational Development, 2014(10):6974. DOI: 


\section{https://doi.org/10.14121/j.cnki.1008-}

3855.2014.10.015

Liu, J. \& Zhu, Y.M. (2018). The impact of teaching efficacy on academic burden: A meta-analysis. Research in Educational Development, 2018(10):6.

Mei, S., Zhu, Z., \& Leng, P. (2021). Research on academic burden from international perspective. Converter, 2021:341-349. DOI: https://doi.org/10.17762/converter.297

Meier, S.T., \& Schmeck, R.R. (1985). The burned-out college student: A descriptive profile. Journal of College Student Personnel, 26(1):63-69.

Meng, X.Y. (2017). Human alienation and regulation in academic burden. Journal of the Chinese Society of Education, 2017(2):25-29 +54 .

Mincer, J. (1958). Investment in human capital and personal income distribution. Journal of political economy, 66(4):281-302. DOI: https://doi.org/10.1086/258055

Morgan, I.G., Ohno-Matsui, K., \& Saw, S.M. (2012). Myopia. The Lancet, 379(9827):1739-1748. DOI: https://doi.org/10.1016/S01406736(12)60272-4

Nakayasu, C. (2016). School curriculum in Japan. The curriculum Journal, 27(1):134-150. DOI:

https://doi.org/10.1080/09585176.2016.1144 $\underline{518}$

OECD. (2012, December 3). PISA 2012 Results. The Organization of Economic Cooperation and Development. Retrieved from https://www.oecd.org/pisa/keyfindings/pisa2012-results.htm

Pines, A. \& Kafry, D. (1980). "Tedium in College." Paper Presented at the Western Psychological Association Meeting, Honolulu, Hawaii (ERIC Document Reproduction Service No. ED192210)

Qi, M.L. \& Sun, C.Y. (2016). The positive role of academic burden in primary and secondary schools. Modern Primary and Secondary Education, 2016(4):76-79. DOI: https://doi.org/10.16165/j.cnki.221096/g4.2016.04.018

Ren, S.Y. (2004). Psychological Effect Theory: A New Strategy for learning Guidance and
Education under the New Curriculum. Hangzhou: Zhejiang University Press.

Rong, X.F. (2017). The construction of assessment index system of academic burden of junior middle school students in Hebei Province. Doctoral dissertation. Hebei Normal University.

Schultz, T.W. (1961). Investment in human capital. The American Economic Review, 51(1):1-17. Available at: https://www.jstor.org/stable/1818907

Song, N.Q. \& Yang, X. (2014). Quantitative analysis on excessive schoolwork of primary and secondary school students. Educational Research, 2014(3):25-30.

Trautwein, U., Lüdtke, O., Kastens, C., \& Köller, O. (2006). Effort on homework in grades 59: development, motivational antecedents, and the association with effort on classwork. Child Development, 77(4):1094-1111. DOI: https://doi.org/10.1111/j.1467$\underline{8624.2006 .00921 . x}$

Wang, S.S. (2014). Focus of the reform in primary and secondary education quality assessment -- Based on the Opinions on Promoting Reform in Comprehensive Assessment of Primary and Secondary Education Quality. Education measurement and Evaluation (Theoretical Edition), 2014(7):20-24. DOI: https://10.16518/j.cnki.emae.2014.07.008 Wolffsohn, J.S., Flitcroft, D.I., Gifford, K.L., Jong, M., Jones, L., Klaver, C.C.W., Logan, N.S., Naidoo, K., Resnikoff, S., Sankaridurg, P., Smith, E.L., III, Troilo, D., \& Wildsoet, C.F. (2019). IMI-myopia control reports overview and introduction. Investigative Ophthalmology \& Visual Science, 60(3):M1M19. DOI: https://doi.org/10.1167/iovs.1825980

Zhang, F. (2020). Essence of academic burden: Students' negative learning experience. Basic Education Curriculum, 2020(9):78-80. DOI: https://10.3969/j.issn.1672$\underline{6715.2020 .09 .014}$

Zhu, X.H., Haegele, J.A., Liu, H., \& Yu, F. (2021). Academic stress, physical activity, sleep, and mental health among Chinese adolescents. International Journal of Environmental Research and Public Health, 
Liu \& Huang (Canada). Evaluation and Analysis of Student Academic Burden.

18(14):7257. DOI:

https://doi.org/10.3390/ijerph18147257

Zhu, X.H., Haegele, J.A., Tang Y., \& Wu, X.P.

(2017, December 24). Physical Activity and

Sedentary Behaviors of Urban Chinese Chil- dren: Grade Level Prevalence and Academic Burden Associations. BioMed Research International. DOI:

https://doi.org/10.1155/2017/7540147

Received: 06 November 2021

Revised: 15 November 2021

Accepted: 07 December 2021 